\title{
TECHNOLOGY AND TEACHING
}

\section{A WORK PAPER FOR AATSP}

\section{by Richard Barrutia}

The technological discoveries of the late nineteenth and early twentieth centuries - the electric light, the automobile, the telephone, the telegraph, the radio, the motion picture, the airplane - had become the common denominators of a new and vastly different way of life all over the world. After two world wars the technological fallout still had enormous impact with the development of tape recording, television, computers, microwave information retrieval, jet travel, and space exploration.

One of the important, and I believe lasting contributions of technology to education in the 60's was programed instruction of various sorts. After the initial smoke caused by false alarms had cleared, there still remained a solid body of ideas, research and tools at the disposal of the real innovators in this field. Unfortunately, those who seized upon what they thought was an opportunity to capitalize on a new trend made it appear to some to be no more than a fad. And indeed, that is exactly what it became for those who developed gadget oriented systems and neglected program oriented systems.

Others who continued to do research and experiment along a more sane course soon realized the potential in programed instruction especially when combined with the power of a computer or other instructional audio-visual media. A few programs of psychologically sound design began to appear as early as 1964 . The progress, however, has been slow and really good self-instructional programing is still a rarity in foreign language learning. Nevertheless this is a technique yet to be contended with and consequently learned by our teachers.

Piaget writes about an early "feedback" (a basic principle in $\mathrm{Pl}$ ) idea in the form of cardboard blocks at the students' desks with different colors on each of the six sides. A question was put to the class along with several possible answers, true-false rejoinder, or simply an "I don't know" rejoinder" whereupon the students would turn the block to signal their answers. The professor could in this way quickly scan the classroom to satisfy himself that enough students were answering correctly or if not to continue with further explanation. 
Some modern devices are direct fallouts of this idea with electrical gadgetry added. A student might have, for instance, a small cylinder in his hand with a lighted rotating top. These are connected to a teacher's console that calibrates the percentage of the class giving the right answer. The students immediate reinforcement is received by a gentle vibration of the coil when he is right or no vibration in the case of a wrong answer but with a light indicating the letter of the correct answer. Many of these "feedback" techniques can be effectively used without any gadgetry whatsoever. For example the teacher could train a class to signal "I understand" by using the closed fist with an upright thumb, "I don't understand" with an open hand, "I understand but how does it relate" by an open hand with palm inward and finally "You're boring me" with a bent wrist loose hand gesture. By this signaling system the professor can alter his lecture to conform with the needs of the majority of the class. It is difficult and requires complete attention and involvement with every idea on the part of the teacher as well as the students. One of the beneficial side effects of the technology of programed instruction is that it serves as an excellent example to the teacher of how to improve teaching and learning procedures. The method cited above is a clear case of a procedure which derives directly from a technological beginning. There are many cases of teachers who have improved their own classroom techniques by carefully scrutinizing the tight organization of some good programed instruction.

The use of media in teaching is an area where much serious education and training still needs to be done where our foreign language teachers are concerned. Because of the nature of language itself. e.g., being multi-modal, a diversfied media can be more reasonably utilized than in teaching other disciplines. One of the most useful items in this regard is the film "Use of Media in Foreign Language Teaching." It should be a must in all foreign language teacher preparation programs.

The language laboratory, like many another of man's tools has taught us much about our material, about our students, and about ourselves. It taught us, for instance, just as the automobile has that we can be carried away by our inventions, (no gag intended). It showed us that our students, for the most part, are not so interested in learning a foreign language that they are willing to subject themselves to hours of sometimes tedious drills as many of us have done. It has given many what they feel is a cautious insight about moving too quickly toward a radical shift in teaching styles. It has given others of us an insight into things to come where automated learning is concerned. And there is no doubt that finally it has given us many headaches as it has given results. Nevertheless, the language labora- 


\section{Technology and Teaching}

tory is here to stay. Whether or not it will be a laboratory without walls as this author described (Hispania, December 1967) or something vastly more sophisticated, the technology of language teaching will be something that all our future teachers will have to study, understand, and employ to keep abreast of the electric age.

The small cassette recorder and the convenient size of the cassette cartridge will undoubtedly have the greatest impact of the equipment presently available. These cassettes are standard throughout the world and are easily co-ordinated with film strip slides and movies. The portability and low cost of these battery operated casette players are also important factors in making them a tool of widespread use. Added to these features are the simplicity of use and a foolproof operation in which the teacher need never thread, splice or even touch the tape itself.

It was surprising to hear at the recent NALLD Conference that a number of specialists are still intent upon acquiring even more random dial access positions for their schools. The mystery lies in the admitted deficiencies of the dial access systems installed to date. These are: 1) The student does not have stop, start nor rewind control of his own program because many others may be listening to it at the same time. 2) The student can tune in on any program but only at the point where the program is at the moment he dials. We thus must wait until it starts again if he dials at any time other than exactly when it is beginning. 3) The number of student positions available is limited to the capacity of the computer on which the system's logistics depends. 4) The student must be at a terminal with the dialing equipment to take advantage of any material.

For such equipment with these built-in problems our schools are paying perhaps twenty times more money than would be necessary to provide students with any material anytime at any place and still give him complete control of the program. The answer is, of course, by simply providing duplicated cassettes and inexpensive cassette players for student use wherever they might want to use them. A number of tape dispensing areas, lab library, etc.; can be set up so that students who own their own machines can simply check out the tapes. For those who do not own machines, play-backs can be checked out on a monthly or even semester basis. Such a system would eliminate all of the deficiencies of dial access, cost much less money, and be infinitely more convenient for both students and teachers.

Perhaps this image will bring the point home more acutely. Imagine a Bolivian Indian walking along a ridge of the Altiplano listening to a tape of English as a Second Language on his eighteen dollar battery-operated cassette player. Now imagine the cost of getting that same information to the same person at his location with com- 
plete control of the program through the dial system. The former is truly information retrieval. The plight of our modern age is the re. striction we place on ourselves by the tendency to favor more complex technology in the face of simple and practical alternatives.

Also in the area of tape cartridges comes one of the most remarkable and educationally promising bits of technology. The Sony Corporation (and very possibly others), will this year, market a small VTR cartridge record and play back unit for less than $\$ 1000$. This portable recorder will drive a cartridge that can be monitored on any home set in either black and white or color. The educational implications of such a system are truly astounding. It can, for instance, lead to collections in public and private libraries of documentary films, learning programs, artistic presentations, drama, music, dance history, etc., that can be used at home. It could easily lead to copying of news documents (sans commercials) then combining them for a historical perspective of any given period. When these items have served their purpose they can, of course, be erased and brought up to date by re-copying just as with any tape recorder. As students of literature or language work through a text they can refer to a dramatized version more readily and more economically than ever before. More and mnre in this way we see learning moving from our classrocms to the home where technology has already made enough inroads in America so as to make the majority of our living rooms well-equipped labs.

Educational television still holds promise even though, like radio, it has been for the most part disappointing. With the exception of special and costly shows like "Sesame Street", most attempts have been frustrated by 1) lack of immediate feedback, 2) competition with extravagant commercial shows and 3) unfortunate time slots. The remaining hope lies in closed circuit television which still needs much research in the areas of logistics, feedback and finally efficacy where foreign language learning is concerned.

All of these isolated little bits of information can add up to substantial increase in teacher effectiveness when they are assimilated as one whole area of knowledge concerning technological media in teaching. The question is then how can we best help our student teachers to assimilate and learn these functions while they are still in training. An answer to this question is to have local and regional conferences of foreign language teacher trainees. We have always had an ample number of such conferences for the working teacher but never for those doing practice, cadet teaching or simply studying toward a teaching credential. Conferences of this nature would certainly give the expectant teacher a start toward professionalism and allow 


\section{Technology and Teaching}

for useful workshops on the use of media and other curriculum matters at the same time.

The judicious use of technological media in our classrooms has been proven by research to be a wide range of aids that release faculty time for the important function of being teachers first and simple information sources second. If these aids were to be widely used in ways described in various reports by a number of specialists in the field they could enhance foreign language teaching dramatically. Here are some of the possibilities that may well be realized through the application of technology in education to the benefit of both students and teachers.

A. As the main role in learning is played by the student himself, each student could proceed at a pace determined by his own capacity and motivation.

B. Tutorial and remedial assistance could be provided for all students during regularly scheduled courses.

C. The formal curricula of lock-step education could be replaced by flexible scheduling and student oriented patterns of study.

D. Large classes at all levels from college to kindergarten could be reduced to small instructional groupings and seminars. This becomes possible because the teacher is free to work with individuals and small groups while the bulk of the students are working at the machines.

E. Special instruction can be given students with insufficient preparation including instruction at home for physically handicapped or bedridden students.

In the final analysis it is safe to predict that the use of media will prove to become what most exploratory research already strongly suggests. It will be 1) economically feasible, 2) educationally effective, and 3 ) enthusiastically received by most students at all levels of age and experience.

There are those in our profession who will balk at still more use of technology in the fear that their own job will somehow become less important. Let them know that our task is to master technology in all of its applications rather than become its slaves. The main purpose of its use is to keep real teaching at a human level and not let our profession degenerate to performing machine-like activities and thereby exemplify the dreaded word "dehumanization."

ABOUT THE AUTHOR:

Mr. Barrutia is the Language Laboratory Director at the University of Califormia, Irvine and is the author of numerous articles dealing with language methodology. 